\title{
Counting and Countenancing
}

\author{
Achille C. Varzi \\ Department of Philosophy, Columbia University, New York
}

[Final version published in Aaron J. Cotnoir and Donald L. M. Baxter (eds.), Composition as Identity, Oxford: Oxford University Press, 2014, pp. 47-69]

I endorse Composition as Identity, broadly and loosely understood as the thesis that a composite whole is nothing over and above its parts, and the parts nothing over and above the whole. Thus, given an object, $x$, composed of $n$ proper parts, $y_{1}, \ldots, y_{n}$. I feel the tension between my Quinean heart and its Lewisian counterpart. I feel the tension between my obligation to countenance $n+1$ things, $x$ and the $y_{i}$ 's, each of which is a distinct portion of reality, and my inclination to count just 1 thing, $x$, or just $n$ things, the $y_{i}$ 's, the former encompassing the same amount of reality as the latter. This paper is an attempt to reconstruct this tension and to explain it away without forgoing the intimate link between counting and countenancing.

Let me begin by reciting my Quinean credo explicitly. This comes in three parts ${ }^{1}$ : (Q1) I believe that there is only one notion of existence, and that such a notion is adequately captured by the existential quantifier. (Q2) I do not draw any distinction between being and existence: to say that there are cats is to say that cats exist, and to say that Tom exists is to say that there is such a thing as Tom. (Q3) I believe that we are ontologically committed to all those entities that must exist in order for the statements or theories that we hold true to be true. In particular, we are committed to countenancing all those entities on which such statements and theories quantify.

My Lewisian credo comes in three parts, too. ${ }^{2}$ (L1) I believe that the parthood relation is extensional: no two composite things have exactly the same proper

\footnotetext{
${ }^{1}$ And it all goes back to Quine [1948].

${ }^{2}$ Here my credo follows Lewis [1991], though it stems more generally from my credo in classical mereology, or the calculus of individuals, as rooted in the work of Leśniewski [1916] and Leonard and Goodman [1940]. In fact, each of L1-L3 below is explic-
} 
parts. (L2) I believe that mereological composition is unrestricted: any non-empty collection of things, no matter how disparate or gerrymandered, has a fusion, i.e., something that has all those things as parts and has no part that is disjoint from each of them. ${ }^{3}$ For example, given that there are cats, there is such a thing as the fusion of all cats - that large, scattered chunk of cat-stuff that is composed of all the cats and nothing else. Given that there are trouts and also turkeys, each of which has a front and a back, there are such things as trout-turkeys - things composed of the front half of a trout and the back half of a turkey. And so on. (L3) I believe that mereology is innocent: ontological commitment to the fusion of some things is no further commitment than commitment to each of them. For example, as Lewis puts it, a cat-fusion is "nothing over and above" the cats that compose it: "Take them together or take them separately, the cats are the same portion of Reality either way", and if we drew up an inventory of Reality according to our scheme of things, "it would be double counting to list the cats and then also list their fusion". ${ }^{4}$ More generally, since L1 and L2 jointly entail that everything is identical with the fusion of its proper parts, L3 may be taken to say that ontological commitment to something is no further commitment than commitment to each of any number of proper parts that compose it. As Donald Baxter put it, the whole is just the parts counted loosely: "It is strictly a multitude and loosely a single thing." It is just the parts collectively "on a strict count", or a single thing "on a loose count". That's why, if you proceed with a six-pack of beer to the 'six items or fewer' checkout line at the grocery store, the cashier is not supposed to protest your use of the line on the ground that you have seven items: either s/he'll count the six bottles, or s/he'll count the one pack.

itly defended by Goodman [1956]. My own reasons for endorsing the three theses are given in Varzi [2008], [2006], and [2000], respectively.

${ }^{3}$ Given L1, any non-empty collection of things can have at most one fusion. In the following, therefore, I will generally speak of the fusion of a given collection. It also turns out that, as long as parthood is transitive and weakly supplemented-in the sense that every composite object has at least two disjoint proper parts-L1 actually follows from L2. (See Varzi [2009] for a proof.) Here, however, I will keep the two theses separate.

${ }^{4}$ Lewis [1991], p. 81. Here is where mereology is supposed to differ from set theory. For assuming we are committed to the existence of cats, we seem to incur further commitment in affirming the existence of their singletons, or of any other set that has cats as members. After all, a set of cats is an abstract entity, whereas a fusion of cats is just as concrete and spatiotemporally located as the cats themselves. However, I will not dwell on this point and will refrain from including the non-innocence of set theory in my Credo.

${ }^{5}$ Baxter [1988], pp. 580f. Recently, Baxter has repented of using "strict" for finegrained counts and "loose" for coarse-grained counts; see his [2013], fn. 3. 
Now, L3 is, of course, grounded on the Composition-as-Identity thesis as I roughly formulated it at the beginning. ${ }^{6}$ And it is this thesis that clashes with my Quinean credo, specifically with Q3. For, on the one hand, surely a composite whole is numerically distinct from each of the things that compose it: it has a different size, a different overall location, etc. Indeed, every whole has a different mereological composition than any of its proper parts; the very notion of a proper part entails non-identity. Thus, on the face of it, the ontology of someone who endorses mereological fusions appears to be richer than the ontology of someone who does not; it countenances the fusions and it countenances the individual things that compose them, each of which is something else. On the other hand, the thought that a fusion is numerically identical to the things that compose it taken together - that the 'are' of composition is really the 'is' of identity in plural form-would vindicate the intuition that such double countenancing is ultimately redundant, hence the innocence thesis. Yet such a thought appears to be a metaphysical "monstrosity", as Plato famously put it. ${ }^{7}$ For as Lewis himself acknowledges, the fusion is one whereas the many things that compose it are many, hence the one cannot be truly identical to the many on pain of giving up the Indiscernibility of Identicals (as, for instance, Donald Baxter has recommended). ${ }^{8}$

Of course, one could bypass the whole problem by saying that a fusion does not exist in the same sense in which the things that compose it exist. Or one could say that the fusion has mere being, whereas the things that compose it exist strictly

${ }^{6}$ Accordingly, I take it that L3 necessitates both L1 and L2. It necessitates L1 insofar as any violation to extensionality would make the innocence claims unintelligible. How can two entities be "nothing over and above" the same collection of things? As for L2, suppose that it is uncontroversial that certain objects exist. If composition were not unrestricted, it would then be a controversial question - the special composition question, in the terminology of van Inwagen [1990] — whether those objects have a fusion. However, it would not be an open question whether they themselves exist. Hence, it would be illegitimate to regard the former as "nothing over and above" the latter. See Merricks [2005], pp. 629f, and Sider [2007], pp. 72f, for arguments along these lines, pace Cameron [2007, 2011]. Strictly speaking, however, L2 is logically independent of Composition as Identity, as shown in McDaniel [2010].

${ }^{7}$ Philebus, 14e. Elsewhere, however, Plato himself has Socrates say that "if a thing has parts, the whole thing must be the same as all the parts" (Theatetus, 204a).

${ }^{8}$ See Lewis [1991], esp. p. 87, and Baxter [1988, 2013], respectively. To be sure, there is a third option: one could view composition as a "generalization" of identity that holds between portions of reality independent of our ways of counting. I will not consider this option here, but see Cotnoir [2013] for a detailed proposal in this spirit that satisfies an appropriately generalized version of the Indiscernibility of Identicals. 
and literally (or vice versa). Neither of these options, however, makes any sense to me, since my Quinean credo also includes Q1 and Q2, respectively: there is only one notion of existence, and to be just is to exist. ${ }^{9}$ So the problem remains. How can mereology be innocent? How can a fusion - a composite entity-be nothing over and above the things that compose it if it is distinct from each of those things and if it cannot be identical to those things taken together?

\section{II}

One popular way of dealing with this question rests on the idea that, although composition falls short of plural identity stricto sensu, the 'are' or composition is none the less relevantly analogous to the 'is' of identity. Lewis himself follows this strategy, as his case for L3 rests on the illustration of several important aspects in which the analogy is supposed to hold. ${ }^{10}$ For instance, just as there cannot be two things both of which are identical with, say, a single cat, there cannot be two things both of which are composed by the same plurality of cats (provided we accept L1). Likewise, just as a cat need not satisfy any special condition for there to be something identical with it, a plurality of cats need not satisfy any special conditions for there to be something composed by them (provided we accept L2). Moreover, just as something identical with a cat must perforce occupy the region of spacetime occupied by the cat, something composed of a plurality of cats must perforce occupy the region of spacetime occupied by the cats. Finally, just as fully to describe a cat is fully to describe something that is identical with a cat, so fully to describe a plurality of cats is fully to describe the fusion of those cats.

I am happy with all this. In particular, since I endorse L1 and L2, I certainly agree that composition is analogous to identity in the first two respects, contrary to some critics. (For instance, van Inwagen explicitly discards the second aspect of the analogy by rejecting L2. ${ }^{11}$ ) However, if this - or something along these lines is all there is to the sense in which composition is analogous to identity, then it can hardly do the job, as there are relations that are equally analogous to identity and that would not qualify as ontologically innocent by any standard. Byeong-Uk Yi's accompaniment relation is a case in point. ${ }^{12}$ Suppose we endorse the following

${ }^{9}$ I say this emphatically, as some critics have objected to the arguments in Varzi [2000] on the grounds that they rest on the sin of literally distinguishing two notions of existence. See e.g. Berto and Carrara [2009].

${ }^{10}$ See Lewis [1991], pp. 85f.

${ }^{11}$ See again van Inwagen [1994].

${ }^{12}$ See Yi [1999]. 
three theses: (A1) Anything whatsoever has exactly one thing that accompanies it. (A2) Whatever accompanies something is not accompanied by it. (A3) The accompaniment of a thing occupies the same region of spacetime occupied by that thing and shares all the "usual" properties that the thing has (as opposed to such "special" properties as its haecceitas or its mereological make-up); in other words, the accompaniment of a thing is a perfect, colocated "duplicate" of it. Evidently, the relation thus defined is analogous to identity in each of the four respects in question: two different things cannot both accompany the same thing; a thing need not satisfy any special condition to have its accompaniment; etc. Yet the theory determined by (A1)-(A3) is everything but ontologically innocent (let alone plausible): a thing's accompaniment would be something over and above the thing itself, no matter how kindly one construes the phrase 'over and above'.

I take it that it is an open question whether a better characterization of the intended analogy between composition and identity can be produced that would suffice to vindicate the weak reading of the Composition-as-Identity thesis, thereby warranting the innocence of mereology. However, I am not aware of any and I have no idea how to produce one myself. ${ }^{13}$ Absent such a characterization, Lewis's account is a useful precisification of the intended meaning of the Composition-asIdentity thesis, but the innocence of mereology remains to be established.

That the thesis must be understood that way is, in fact, not as obvious as it might seem. I have mentioned Lewis's (and Plato's) worry that reading the 'are' of composition literally as a plural form of the 'is' of identity be metaphysically intolerable, for it appears to violate the Indiscernibility of Identicals - and this is a popular view. ${ }^{14}$ However, there are ways of challenging this conclusion. One could, for instance, turn to Frege and to his notion of relative counting, as suggested e.g. by Megan Wallace and Shieva Kleinschmidt. ${ }^{15}$ For Frege, it makes no sense to count things tout court; the ascription of a cardinality is always relative to the concept or sortal under which we are counting-how many $F$ s? how many $G$ s? - and this naturally applies to the counting of pluralities. "The Iliad-he says in the Grundlagen - can be thought of as one poem, or as twenty-four books, or as some large number of verses". ${ }^{16}$ Likewise, "a pile of cards can be thought of as

${ }^{13}$ Sider [2007], pp. 77-78, goes some way towards a stronger characterization of the analogy between composition and identity, but stops short of claiming that it warrants the innocence thesis.

${ }^{14}$ The worry is stressed e.g. in van Inwagen [1994], Yi [1999], and McKay [2006], pp. 38f.

${ }^{15}$ See Wallace [2011] and Kleinschmidt [2012].

${ }^{16}$ Frege [1884], §22. 
one pack or as fifty-two cards" and "one pair of boots can be thought of as two boots". ${ }^{17}$ The phrase 'can be thought of' introduces some complexities, but never mind. One could still build on Frege's view to save the strict reading of Composition as Identity and claim that the whole just is, strictly and literally, the parts. The poem just is the books, or the verses: it is the books, or the verses, when counted under the concept poem. If so, then Lewis's worry would not apply: it's not that the poem is one and the books, or the verses, are many; rather, the poem qua poem is one and the books qua books, or the verses qua verses, are many. But the books, or the verses, qua poem are one and the poem qua books, or qua verses, is many.

The idea that Composition as Identity involves a relative notion of counting as opposed to different senses or notions of existence, or of identity - is indeed attractive and for a friend of qua objects this may very well sound like a good way out of the problem. No need to treat composition as merely analogous to identity, and no need to give up the Indiscernibility of Identicals, either; rather, as Frege himself put it, "what changes here is not the individual or the whole, the aggregate, but our terminology". ${ }^{18}$ Unfortunately, I am not a friend of qua objects, so I can't find satisfaction in this proposal. I'm afraid here is where my Quinean heart trumps its Lewisian counterpart. I am also skeptical about the possibility of providing an adequate characterization of the relevant notion of a "sortal", popular and widespread as it may be among contemporary philosophers. But even if someone felt differently about that, there is an important, independent reason why the proposal itself won't quite do. For as Baxter pointed out, Fregean counting will not always deliver the desired verdicts. Specifically, it will not avoid double-counting when the whole and the parts are homeomerous, i.e., when they fall under the same sortal. ${ }^{19}$ Perhaps a fusion of verses is not itself a verse, as a fusion of shoes is not a shoe and a fusion of cats is not a cat. But suppose we build a large cat statue, $x$, out of many small pieces, $y_{1}, \ldots, y_{n}$, each of which is itself a cat statue. ${ }^{20}$ If mereology is innocent, then the large statue is nothing over and above the small ones:

${ }^{17}$ Frege [1884], 22 and $\S 25$.

${ }^{18}$ Ibid., \$46. In the same context, Frege gives us one more example of many-one identity without using the opaque 'can be thought of' phrase: "While looking at one and the same external phenomenon, I can say with equal truth both 'It is a copse' and 'It is five trees', or 'Here are four companies' and 'Here are five hundred men'".

${ }^{19}$ See Baxter [2005], p. 378.

${ }^{20}$ There are actual examples of statues of this sort. A remarkable one is Manolo Valdés's La Dama Ibérica (València, 2007), which is composed of 22,000 small copies of La Dama de Elche (an ancient sculpture from 5th, perhaps 4th century B.C.). Many thanks to Jordi Valor for bringing my attention to it. 
either we count just 1 thing, $x$, or just $n$ things, the $y_{i}$ 's, the former encompassing the same amount of reality as the latter. Yet on a Fregean counting we'll have to count $n+1$ things, since each of them falls under the same sortal cat-statue.

Besides, the worry about the metaphysical "monstrosity" of the strict construal of Composition as Identity is not the whole story. For, on closer inspection, reading the 'are' of composition literally as a plural form of the 'is' of identity appears to be logically intolerable, too. It appears to be logically intolerable because the apparatus of plural quantifiers, predicates, and referring expressions would not behave as expected, on pain of restricting the law of substitutivity in extensional contexts (as, for instance, Paul Hovda has recommended ${ }^{21}$ ). Here is the sort of misbehavior I have in mind. Ted Sider has shown that the reading in question would imply a collapse of the relation expressed by the predicate 'is one of' onto the parthood relation: something is one of a plurality of things if and only if it is part of the fusion of those things. ${ }^{22}$ However, this would imply the failure of the basic principle according to which something is one of a plurality of things if and only if it is identical to one of those things (for, generally, those things may have proper parts, all of which would count as parts of their fusion). And if 'is one of' does not obey that principle, then its logic — and not just its linguistic behavior, as critics such as Peter van Inwagen have complained ${ }^{23}$-is up for grabs. ${ }^{24}$

I conclude that the weak reading of the Composition-as-Identity thesis, according to which the 'are' of composition is merely analogous to the 'is' of identity, is indeed the only tenable one. ${ }^{25}$ Yet the fact remains that the analogy does not, by itself, suffice to warrant the innocence of mereology. Resolving the tension between L3 and Q3 calls for a different strategy.

\section{III}

I do not, in fact, believe that there is a simple way of arguing for the innocence of mereology from the Composition-as-Identity thesis. Suppose you are ontologically committed to such things as cats. Your theory of the world quantifies over cats,

${ }^{21}$ See Hovda [2006].

${ }^{22}$ See Sider [2007], pp. 57f.

${ }^{23}$ See van Inwagen [1994].

${ }^{24}$ Further problems deriving from the collapse of 'is one of' onto parthood are discussed in Sider [2013].

${ }^{25}$ As I said, I am not considering here the option of treating composition as a "generalization" of identity, as in Cotnoir [2013]. That option would be immune to some of the logical problems just mentioned, as Sider's collapse argument would not go through. 
and you happily share my Quinean credo, including Quine's criterion for ontological commitment, Q3. If there are cats, I say there are also cat-fusions, by L3, so I claim that you are committed to such things, too, though really this should not count as a further commitment: a cat-fusion is nothing over and above the cats that compose it. No cat-fusion, however, is a cat, except in trivial cases, and your theory only quantifies over cats. Why should you accept my claim? For another example (actually discussed in the literature ${ }^{26}$ ), suppose you are ontologically committed to Tom, whom you know to be a cat, and to Jerry, whom you know to be a mouse. No cat has a mouse as a part, and no mouse has a cat as a part, or so we may assume. (Your theory may say so explicitly.) But if Tom exists and Jerry exists, I say their mereological fusion exists, too, call it 'Genie', so I claim that you are committed to three things, Tom, Jerry, and Genie, though really the third thing is nothing over and above the first two. Why should you accept my claim? Genie is neither a cat nor a mouse, since it has a cat-part, Tom, as well as a mouse-part, Jerry. Why should you agree that your ontological commitment to a cat and to a mouse carries with it a commitment to something that is a genuinely different kind of thing, innocent as such a commitment might be? There is no straightforward answer to questions such as these, on pain of begging them. The only reasonable way for me to try and convince you would involve a long story about reference and natural-kind terms, and on my reckoning the success of my story would depend on my ability to steer you toward a conventionalist, broadly nominalist understanding of these notions. That is all fine and I'd be happy to spell it out for you, if you asked me. But it just goes to show that something more than the weak reading of Composition as Identity is needed to establish the innocence thesis, L3, against our shared Quinean credo.

None the less there is, I think, a way of elucidating the Composition-asIdentity thesis (in its weak reading) that fares better than the mere analogy strategy. It fares better in warranting, if not the truth of L3 strictly and literally, at least the truth of a certain way of understanding L3 - one that preserves the spirit of Lewis's innocence claim without sinning against Quine. I will first illustrate the general idea informally, and then add some points of detail.

Picture this. You are taking your first exam in Ontology. You enter the room and Professor Q. asks you the three-word question you have been expecting: What is there? Having studied the books, you are familiar with theses Q1 through Q3, and you answer the question by listing all the things that must exist in order for the statements or theories that you hold true to be true. At least, you begin to produce

\footnotetext{
${ }^{26}$ In Yi [1999].
} 
such a list, for the task may be impossible to carry out in full. Here is a snapshot of the very beginning of your list:

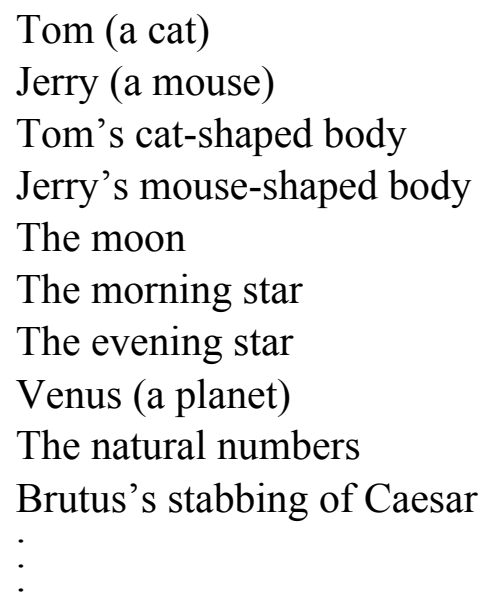

Professor Q. asks you whether all those things exist in the same sense, and you answer: Yes. He also asks you whether you think that there are things that do not exist, and whether you would like to add them to the list, and you answer: No, there are no such things; to say that there are things that do not exist would be a contradiction in terms. Professor Q. is happy with your answers and, while he might not agree with the actual content of your list, he reckons you know what you are doing and gives you the good grade you were hoping for. But he gives you a piece of advice. "This list-he says - is redundant. At least, I think it is. In some cases, you have listed the same item more than once under different descriptions, or with different names. It is true that I have only asked you 'What is there?', and answering that question does not require that you check for redundancies; as long as the list aims to be complete, the answer is fine. But I advise you to check for redundancies none the less. In some cases, it is just a matter of empirical knowledge. (As far as I know, astronomers have established that the morning star, the evening star, and the planet Venus are one and the same thing.) In other cases, it may require metaphysical decisions. (For instance, I wouldn't draw any distinction between a cat and its body. Animals are their bodies, though I reckon you may have different views.) Either way, keep in mind that drawing up a complete inventory of what there is is just the beginning of a good philosopher's job. Making sure that it isn't redundant is just as important, difficult and time consuming as that task might be." ${ }^{27}$ You thank professor Q. for his advice and get ready to spend

${ }^{27}$ Here I am taking Professor Q. to draw a sharp distinction between ontology, understood strictly as that part of philosophy that deals with the question of what entities exist, 
the rest of the semester studying astronomy along with metaphysics (and much more) to produce a sharper list of your commitments. You want to be a good philosopher, not just a plain ontologist.

As it turns out, your next class is Mereology, which you soon learn to be the theory of parthood relations - the relations of part to whole and the relations of part to part within a whole. You learn that some philosophers deny that there exist such things as proper parts; others believe that while there are such things, they only exist in potentia. You disagree with both. You become convinced that a good theory of the world should quantify over all sorts of parts, not just over the wholes to which they belong, and to quantify over something is to countenance its existence, in the only sense of 'exists' that you have learned to recognize. Thus, you go back to the list you had prepared for Professor Q. and start adding a number of things that —as you now realize — were missing:

Tom (a cat)

Tom's head

Tom's tail

Tom's torso

The top half of Tom's torso

The middle third of Tom's torso

Tom's heart

Tom's cardiac muscle cells

The cell nuclei

The DNA molecules in the nuclei

It doesn't take long before you become aware of the impossibility to fully spell out the contents of the list, but never mind. When you proudly go back to Professor Q. to show him the initial segment of your revised list, he congratulates you: "Keep going. This looks like as complete an ontological inventory as I can think of. And as far as I can see, there are no redundancies!” Your Mereology teacher, however, reacts differently: "I appreciate your efforts, but don't you think you are overdoing it? Surely all the items you have listed are numerically distinct. But don't you see?

and metaphysics, which seeks to explain, of those entities, what they are. I myself take that distinction seriously, as detailed in Varzi [2011], and I reckon Quine would concur. In particular, I take his precept, "No entity without identity" (Quine [1958], p. 20), to express a minimum condition for drawing up a good, "philosophically responsible" inventory of the world, not a precondition for figuring out our ontological commitments. 
They are all part of the same thing - a cat. If you want to draw up a good inventory of the world, you should avoid such redundancies. Either you list the whole cat, or you list its parts. There's no point in listing both, as they encompass the same amount of reality. I advise you to revise your list accordingly." You thank professor L. for his advice, but you kindly reply: "It is important that I list both. I have learned that some philosophers would share my ontological commitment to Tom but not my commitment to its proper parts, such as Tom's head and Tom's torso. And among those who share my latter commitment, there are some who would not agree in further countenancing "arbitrary" parts such as the top half or the middle third of Tom's torso. I understand there are also philosophers who only countenance the parts - some parts-but not the whole except under special composition conditions. So I have to be precise. I must list all my commitments, as Professor Q. has taught me, on pain of leaving my ontological credo underspecified. Otherwise I could as well list just one thing, the Universe, the sum total of all there is, and leave it at that." Indeed, coming to think of it, you realize that your list is still incomplete. "I forgot to list the Universe explicitly. And I also have to list all sorts of intermediate mereological fusions, for I endorse unrestricted composition. Since I countenance Tom and I countenance Jerry, I should also list the fusion of Tom and Jerry. Since I countenance the top half of Tom's torso and the right half of Jerry's head, I should also list their fusion. And so on. I have to list all the fusions, just as I have to list all the parts, for strictly speaking they are all distinct, and I have learned that some philosophers would not share my commitment to such things. I still have a lot of work to do!" To this, Professor L. responds as we may expect. He says that such work would be useless; that those fusions encompass the same amount of reality as the things that compose them, just as an ordinary whole encompasses the same amount of reality as the parts that make it up; that there is no point in listing both; et coetera.

Now, as you ponder the situation, it seems to me that your natural reaction will be to think that Professor Q. and Professor L. appear to disagree on the relevant notion of a good inventory. The Ontology professor wants your inventory to list all the things you are committed to, and advises you to avoid any redundancies stemming from the presence of items that stand in the identity relation to each other (insofar as you know or believe so). The Mereology professor has a more selective notion in mind, one that makes ample use of the intuitive notion of "portion of reality": he thinks the items in your inventory should cover all the reality you are committed to, and advises you to avoid any redundancies stemming from the presence of items that stand in the composition relation to one another. To put it differently, Professor Q. advises you against double countenancing; Professor L. ad- 
vises you against double counting. If composition were just a kind of identity relation - the many-one identity relation - the two notions would ultimately coincide. But composition is not an identity relation, so you feel the tension. What is the best way to draw up an inventory of your ontological commitments?

As you keep pondering, it strikes you that Professor Q.'s advice is not as straightforward as you initially thought it was. You have two friends, Ali and Baba, who have very similar philosophical views. In fact, they agree on just everything, except when it comes to the person-body problem. Neither is a dualist and both are materialists. But whereas Ali is a eliminative materialist, Baba is a reductive materialist. Ali believes that there are no persons; just human bodies. Baba believes that persons exist, though they are not distinct from their bodies; a person just is a human body. How would they draw up an inventory of their commitments in accordance with Professor Q.'s directives? Surely Ali's inventory will not include any persons; it will only list human bodies (along with whatever else he is willing to countenance). But the same is true of Baba: assuming that her inventory includes human bodies (along with whatever else), it will not also include persons, on pain of double countenancing. Thus, their inventories will coincide, and Professor Q. will have to agree that both have done their job properly. Yet it strikes you that Ali and Baba do not seem have exactly the same ontological views: when confronted with the question "Do persons exist?", their answers will differ.

You have other friends, including Alf and Beth. These two friends of yours share exactly the same philosophical views as Ali and Baba, except when it comes to the person-body problem. Like Ali, Alf is an eliminative materialist. But his eliminativism does not only concern persons; it concerns human bodies, too. In his view, there are no such things; there are just particles arranged human-wise. Beth, by contrast, is a reductive materialist, like Baba. But her reductionism does not only concern persons; it concerns human bodies, too. In her view there are such things, but they are nothing over and above the particles that compose them; a human body, or person, is just the mereological fusion of a plurality of particles arranged human-wise (the same particles that Alf countenances). It is hard to resist the intuition that the slight disagreement between Alf and Beth is perfectly parallel to the disagreement between Ali and Baba. And yet, it strikes you that in this new case the disagreement would show up if Alf and Beth drew up their inventories in accordance with Professor Q.'s guidelines: Beth's inventory would include persons, i.e., human bodies, i.e., fusions of particles arranged human-wise; Alf's would not. It is only when their inventories are drawn up in conformity with Professor L.'s guidelines that the difference would — or rather, could - fail to show up. For assuming Beth decides to go for a fine-grained inventory and to include the 
particles (along with whatever else), she would not also include their fusions, on pain of double counting. Thus, her inventory would coincide with Alf's, and Professor L. would concur that both have done their job properly.

Now, this parallel between the two cases, or perhaps I should say this asymmetry, is both disturbing and instructive. It points, I think, to a deeper similarity between the two notions of an inventory than you initially thought. For, on the one hand, neither type of inventory reveals the full story about your friends' ontological commitments. Ali's and Baba's Q-type inventories may be silent about their disagreement concerning the existence of persons; Alf's and Beth's L-type inventories may be silent about their disagreement concerning the existence of human bodies. On the other hand, notice that both types of inventory could reveal the full story. For they would reveal it if your reductionist friends decided to produce their lists in terms of the reduced entities instead of the basic ones-Baba in terms of persons (as opposed to the bodies they are identical with) and Beth in terms of human bodies (as opposed to the particles that compose them). In other words, the richer ontological commitments of the reductionist vis-à-vis the eliminativist - the realist vis-à-vis the anti-realist, if you like-may or may not show up depending on how Baba and Beth decide to give expression to those commitments. And this applies to both cases - Baba's Q-type inventory and Beth's L-type inventory.

It is this parallel, I submit, that motivates the Composition-as-Identity thesis (even on its weak reading). And it is this sort of motivation that justifies the claim that mereology is ontologically innocent, thereby dispelling the apparent tension between the Quinean and the Lewisian ways of assessing our ontological commitments. For in both cases one can argue that the disagreement between your two friends may - in an important sense - be degraded to a matter of verbal disagreement. And to the extent that their disagreement may be so degraded, it carries no substantive ontological weight. Ontologically, Baba's and Beth's "further" commitments to persons and to human bodies (respectively) are innocent.

\section{IV}

I say 'degraded' because I do not think that the disagreements in question are merely verbal - not in the sense in which some philosophers think that, for instance, the dispute between various metaphysics of material objects, or the more specific dispute between enduratism and perdurantism, are merely verbal. ${ }^{28}$ It's not that your eliminativist friends and your reductionist friends are speaking dif-

${ }^{28}$ As argued e.g. by Sidelle [2002] and Hirsch [2002, 2011]. 
ferent but intertranslatable languages. If so, there would be no fact of the matter as to whether we live in the world of the eliminativist or the world of the reductionist, and at least in the case of Alf and Beth there is a fact of the matter: their worlds have a different cardinality. Rather, the thought is that in both cases your friends can reach an agreement concerning the appropriate way to talk about the world in such a manner as to deliver the full story without remainder. They could agree to speak one and the same language and assert the same truths without forgoing any of their beliefs about the way things are.

The case of Ali and Baba is straightforward. ${ }^{29}$ When Ali says that persons do not exist, he is saying that 'person' is an empty term, i.e., that 'is a person' has an empty extension. After talking to Baba, however, he could easily change his mind and decide to speak exactly like her for ease of future communication. He could decide to use 'person' to refer to human bodies - whose existence he endorsesand to interpret 'is a person' as coextensive with 'is a human body'. And he can decide to do the same with any other predicate that he has been treating as having an empty extension while Baba has been using it to describe what persons do and how they are-say, psychological or action-theoretic predicates. After all, if persons are human bodies, those predicates have human bodies in their extensions and Ali should feel free to start using them just like Baba: any sentence involving such predicates would express propositions about human bodies that Ali is already disposed to assert using other predicates. Likewise for Baba: she, too, could decide to speak like Ali and give up her way of using 'person' and related predicates as nonempty but pleonastic terms. Awkward and uncomfortable as this way of speaking might sound to her, it would "leave out nothing", as Feigl famously put it. " (The discomfort itself may vary depending on whether Baba is a type-type or a tokentoken identity theorist, but we need not go into the details here.) Either way, it is obvious that such a decision would involve no revision whatsoever at the ontological level. Ali, or Baba, would answer the question 'Do person exist?' differently than before. But this would merely amount to a revision in the semantic protocol of their respective idiolects, and the ideologies that they reflect; nihil novi sub sole. ${ }^{31}$ Such is the thin line between eliminativism and reductionism when the latter is cashed out in terms of strict identity. ${ }^{32}$ And the thinness of the line explains

${ }^{29}$ At least, I see it as straightforward, though I am aware that some would disagree, e.g. following Kim [1998].

${ }^{30}$ Feigl [1967], p. 138.

${ }^{31}$ This is how I read Quine [1951].

${ }^{32}$ See Quine's own skepticism about the difference between elimination and reduction, or explication, in his [1960], esp. p. 265. 
why Ali and Baba's initial disagreement need not show up in their Quinean inventories unless Baba resolves to use 'person' rather than 'human body' to give expression to her commitments.

Now consider the case of Alf and Beth. If composition were identity in the strict and literal sense - if the fusion of a plurality of particles were strictly and literally identical to that plurality - then obviously a perfectly parallel argument would apply. Alf and Beth would completely agree on what there is; it's just that they would attach different semantics to the term 'human body'. The innocence of mereology would then follow trivially. ${ }^{33}$ On the other hand, since composition is not identity in the strict and literal sense, the argument may founder. Yet one can still degrade the disagreement between Alf and Beth to a matter of disagreement in their respective idiolects. This involves three steps.

Step one. In Alf's idiolect, 'human body' is an empty term, whereas in Beth's idiolect it is a non-empty term whose extension includes things, human bodies, that are fusions of other things, particles arranged human-wise. Since Alf is committed to the existence of the latter, it wouldn't be a big deal for him to start using 'human body' as a non-empty term, too. He could start using that term to refer, plurally, to those collections of particles whose fusions fall under the extension of 'human body' in Beth's idiolect. That is, Alf could start using 'human body' in such a way as to assent to statements of the form ' $y_{1}, \ldots, y_{n}$ are a human body' if and only if Beth assents to 'the fusion of $y_{1}, \ldots, y_{n}$ is a human body'. And doing so would not be a big deal insofar as it would require no revision whatsoever of Alf's ontological views; just a minor revision in his linguistic practices.

Step two. Suppose Alf revises his idiolect as just described. Now that both Alf and Beth use 'human body' to refer to things that appear in their respective inventories, there is still a difference: in Alf's idiolect, 'human body' functions as a predicate of pluralities (like 'flock' or 'crowd'), whereas in Beth's idiolect it is an ordinary predicate that is true of individual things, viz. the fusions of those pluralities. Alf cannot switch entirely to Beth's way of speaking, because his ontology does not countenance such fusions. However, Beth can certainly switch to Alf's way of speaking, for her ontology does countenance the pluralities that compose those fusions.

Step three. Suppose that, for ease of further communication, Beth revises her idiolect as just described. Then 'human body' comes to have exactly the same meaning in both idiolects. This is not to say that Alf and Beth will now assert ex-

${ }^{33}$ Foes of Composition as Identity would agree. See e.g. van Inwagen [1994], pp. 209, and Baker [2008], pp. 9ff. 
actly the same sentences. For Beth's idiolect may still contain singular terms that refer to those fusions that are missing from Alf's inventory, and Beth will be perfectly happy to assert sentences containing such terms. However, we are assuming that she is a reductionist. She firmly believes that each fusion of particles arranged human-wise is nothing over and above the particles that compose them: every truth about such a fusion, $x$, reduces to a truth about the corresponding particles, $y_{1}, \ldots, y_{n}$. Thus, in principle Beth could decide to speak only truths of the latter sort. It might be difficult for her to actually do so. That is, it might be difficult for her to actually forgo every statement of the form ' $x$ is $P$ ' in favor of a corresponding statement of the form ' $y_{1}, \ldots, y_{n}$ are $Q{ }^{34}$ (though Alf should be able to help her out). That is one good reason why she refrains from endorsing eliminativism holus bolus. None the less, at least in principle she ought to be able to do so. Precisely because she is a reductionist about human bodies, she ought to regard all statements of the first sort as ultimately redundant: they add nothing to the true story about the world. And if those statements are redundant, then the ontological commitments that come with them are, as we may finally put it, innocent.

\section{V}

Now, I take it that the case of Alf and Beth can be generalized. There is nothing special about the source of their disagreement - the person-body problem - that cannot be applied to other cases where philosophers disagree about the existence of things composed by other things to which they are equally committed. That is, there is nothing special as long as the composite entities in question are seen, by the philosopher who countenances them, as fully reducible to the things that compose them. Nor is there anything special about the sort of reduction that is typically involved in the context of the person-body problem. As long as the fusions are seen as doing no genuine metaphysical work over and above the work of the things that compose them, the disagreement between the two parties can be degraded to a matter of verbal disagreement in the way illustrated by Alf and Beth's case. Perhaps 'reduction' is not always the best term; 'grounding' might be better, or 'supervenience', as long as the latter notions are meant to capture the idea that what is grounded or supervenes adds nothing substantive to what grounds or subvenes it.

${ }^{34}$ This is admittedly a simplistic description of what is involved in the linguistic task I'm attributing to Beth, but we need not go into more detail. For a thorough picture of the complications, see Hovda [2005]. 
Let me stress, however, that no matter how exactly one cashes out this "ontological free lunch", in David Armstrong's phrase, ${ }^{35}$ it is not just a matter of linguistic tolerance and dexterity. As I mentioned, I am not denying that the disagreement between Alf and Beth - and, more generally, between those who do and those who do not countenance mereological fusions - is genuine. On the contrary, there is a fact of the matter concerning whether we live in Alf's world or in Beth's, and that is why their Quinean ontological inventories do not coincide. There is, therefore, genuine work to be done on both sides to defend their respective views. And there is genuine work to be done on Beth's side to show that her further commitments can be deflated, just as there is work to be done on Alf's side to defend the sufficiency of his fewer commitments. As Kit Fine put it, any innocence claim must concern "the subject matter itself", not just the means by which it might be represented or cognized. ${ }^{36}$ But my goal here is not to defend Beth's point of view. It is not to defend Composition as Identity as it is not to defend Unrestricted Composition, for I am assuming both at the very start. Rather, my concern is to explain away the apparent tension between such an assumption and my background Quinean credo. That is a tension that arises at the level of ontological commitments. And I am suggesting that the possibility of speaking the language of someone who does not countenance the effects of mereological composition-the possibility of telling the full story about the world in such a language, as illustrated by Beth's case-vindicates the sense in which commitment to such things may be viewed as innocent. Innocent, not nil.

This, then, is how I propose to resolve the tension. L3 says that commitment to the fusion of some things is no further commitment than commitment to each of them. We saw earlier that if this is taken to mean that commitment to the fusion is just the same as commitment to each of those things, then on the weak reading of Composition as Identity L3 would sin against Quine. But that is not the only plausible understanding on L3. I propose instead that we understand it as follows: commitment in one's ontological theory to the truths about the fusion amounts to the same as commitment to the truths about those things, individually and collectively. If we understand it this way, then L3 is still in keeping with the spirit, if not the letter, of Lewis's innocence claim. And the case of Alf and Beth illustrates that it is also in keeping with Quine's ontological wisdom.

Three more points require emphasis. First, precisely because I have not been directly concerned with defending Beth's point of view, or Composition as Identi-

\footnotetext{
${ }^{35}$ Armstrong [1997], p. 13.

${ }^{36}$ Fine [2001], p. 11.
} 
ty more generally, a fortiori I am not saying that the argument above establishes the innocence of mereology. Obviously, one may still think that some composite wholes exemplify properties and relations that are not reducible to or grounded on the properties and relations exemplified by the things that compose them, in which case commitment to the former would be a significant ontological addition to commitment to the latter. Rather, the point of the argument is to clarify the idea that mereology can be innocent: that it is innocent on the assumption that there aren't irreducible wholes like that, which is what Composition as Identity amounts to (even on the weak understanding of 'as' that I have endorsed). Indeed, Composition as Identity is a metaphysical thesis: if true, it must be necessarily true. The very possibility that there be irreducible wholes would therefore suffice to establish the falsity of the thesis, as Kris McDaniel has argued ${ }^{37}$, and nothing I have said so far rules out that possibility. But so be it. My present concern is purely meta-ontological: I am happy enough if the argument succeeds in elucidating the sense in which I take the thesis in question to warrant the innocence of mereology, hence the internal coherence of my Quinean-Lewisian credo. That the thesis itself is true, and true as a matter of metaphysical necessity, is part of the credo.

Second, although the argument rests on the idea that Beth's additional commitments can be deflated away by readjusting her way of speaking, it should not be taken to imply that those commitments are pointless. More generally, I do not intend to imply that vindicating the innocence of mereology along the lines I have been suggesting should have any impact on the value of countenancing composite entities in addition to the smaller things that compose them. It is one thing to say that we can avoid reference to or quantification over such entities; quite another to say that we should do so, or that the very possibility of doing so entails that we ought to endorse mereological nihilism (the view that there are no composite entities whatsoever). And it's not just that the relevant linguistic adjustments may be difficult to implement, as I mentioned in connection with Beth's reasons for preferring reductionism over full-blown eliminativism. There may be genuine metaphysical reasons for resisting the inference. For instance, the nihilist is committed to there being mereological simples (atoms); not so if you countenance the existence of composite entities. In particular, someone who endorses Composition as Identity may say that, at any level of mereological decomposition, a whole is nothing over and above its proper parts, regardless of whether one can reach a bottom level of partless simples out of which everything else is composed. That is why the strategy illustrated above with regard to Beth's case applies irrespective of the

\footnotetext{
${ }^{37}$ See McDaniel [2008].
} 
mereological complexity (if any) that Beth attributes to the "particles" she and Alf agree upon. ${ }^{38}$ The line between reductionism and eliminativism is thin, but it does show up when the former is cashed out in terms of composition rather than strict identity.

Third, I reckon that Beth's case does not do justice to the idea that the innocence of mereology goes in both directions, an idea that I take to be part and parcel of Composition as Identity even on its weak reading: just as the whole is nothing over and above the parts, the parts are nothing over and above the whole. ${ }^{39}$ That is because Beth is a top-down reductionist. She holds that the parts are more fundamental than the wholes to which they belong, with metaphysical explanation proceeding from below upwards. Suppose, however, that she held the opposite view, i.e., suppose she took each human body to be prior to the many particles that compose it, with metaphysical explanation going downward. And suppose that Alf, too, held his view in the reverse: rather than being an eliminativist about human bodies, he is an eliminativist about their proper parts, including the particles that compose them. Then one could run the argument dually: given a human body, $x$, composed of a plurality of particles, $y_{1}, \ldots, y_{n}$, Beth is in principle committed to the possibility of rephrasing every statement of the form ' $y_{1}, \ldots, y_{n}$ are $Q$ ' by means of a statement of the form ' $x$ is $P$ ' to which Alf would assent. Beth's commitment to $y_{1}, \ldots, y_{n}$ would then carry no metaphysical weight, and in that sense it would be innocent - as innocent as her commitment to $x$ in the original scenario.

This is not to say that Composition as Identity is metaphysically loaded. The point is not that in order to hold on to the thesis, and consequently to the innocence of mereology, one has to figure out the direction of explanation and endorse a specific view about what is prior to what. Quite to the contrary. The point is that the truth of Composition as Identity does not depend at all on one's specific views about such matters. Whether you give priority to the wholes or to the smaller parts that compose them, you are dealing with the same "portions of Reality" and you can talk about those portions either way. That's what the thesis says. At least, that is what I am saying it says. And that is why I take the thesis to express a general truth. Composition as Identity does not only apply to middle-size composites, such as human bodies or cat-fusions. It applies across the board, from Proclian monism

${ }^{38}$ This is also why I do not take the dispute between mereological nihilism and universalism (i.e, unrestricted composition) to be ultimately a matter of arbitrary choice (Slater [2005]). See also the discussion in Rosen and Dorr [2002], §8 (though they opt for nihilism).

${ }^{39}$ On the strong reading, where composition is identity in the strict and literal sense, this is of course a consequence of the symmetry of identity. 
à la Schaffer, according to which there is but one, all-encompassing whole on which everything depends (the entire cosmos), ${ }^{40}$ to all sorts of Epicurean atomism, according to which everything is composed of and depends on mereologically simple parts. Indeed, we have seen that the thesis is also compatible with the possibility that the world consist of bottomless "gunk", with everything dividing forever into smaller and smaller parts. It is compatible, too, with the possibility that the world consist of topless "junk", with everything merging forever into larger and larger wholes. ${ }^{41}$ As long as you have some things that are composed of other things, the thesis and its underlying rationale apply regardless of the direction of your metaphysical explanation and regardless of whether the explanation comes to an end.

This last remark is especially important for someone with my QuineanLewisian credo, as it sheds further light on the question, What is the point of countenancing things that don't count? For precisely because you may think that the explanation does not come to an end, or because you have not fully worked out your views on whether or how it will, an L-style inventory may be the only way to express the essence and full scope of your views on what there is. With the only exception of junky worlds - which, however, are ruled out by Unrestricted Composition ${ }^{42}$-an L-style inventory can cover all the reality you are committed to even when a complete Q-style inventory, listing all the things you are committed to, would not be an option. And yet there is no best way to draw up an L-style inventory. As long as it covers all the reality, it is complete. And as long as it doesn't cover any portion of reality twice, it is well done regardless of the "level" at which it is drawn.

There is, none the less, a final question that you may still ask your Mereology professor. For you know what it takes for your inventory to cover all the reality you are committed to: its fusion should equal the Universe. But how can you make sure that it be a good cover, one that avoids the redundancy of covering

${ }^{40}$ See Schaffer [2010]. Schaffer explicitly rejects Composition as Identity, but only insofar as it is understood in the stronger, literal sense of 'as' as 'is'.

41 'Gunk' comes from Lewis [1991], p. 20, and the possibility that the world be so structured has been defended, e.g., by Sider [1993]; 'junk' comes from Schaffer [2010], p. 64 , and the possibility that the world be so structured has been defended, e.g., by Bohn [2009].

${ }^{42}$ L2 implies that the collection of everything composes something, the Universe. But the Universe cannot be a proper part of anything. Thus, a world satisfying L2 cannot be junky (though gunky worlds are perfectly compatible with L2 and the rest of classical mereology, as already shown by Tarski [1935]). 
some portions of that reality twice? Composition as Identity delivers an obvious criterion:

CI If $x$ is the fusion of the $y$, and each of the $y$ s is distinct from $x$, your inventory should include $x$ if and only if it does not include the $y$ s.

Yet this is just the beginning. Surely Professor L. would not be satisfied if you cleaned up your list by dropping all of Tom's parts except for, say, its tail. Such an inventory would comply with $\mathrm{CI}$ - it would include no $y$ s distinct from Tom such that Tom is the fusion of the $y \mathrm{~s}$ - but the inclusion of the tail in addition to the whole cat would certainly be redundant. Nor would it suffice for you to rely on the obvious strengthening of $\mathrm{CI}$ :

$\mathrm{CI}^{\prime}$ If $x$ is the fusion of the $y \mathrm{~s}$, and each of the $y$ s is distinct from $x$, your inventory should include $x$ if and only if it does not include any of the $y$ s.

This would still allow you to list the top half and the bottom half of Tom's torso along with its middle third (or a trout, a turkey, and the corresponding troutturkey), though the latter would obviously be redundant. Composition as Identity is a thesis to the effect that mereological composition is ultimately innocent, but it doesn't automatically translate into an effective criterion for inventorial adequacy. Is there such a criterion? If you are a monist, you could settle on drawing up an inventory including just one thing - the Universe. If you are an atomist, you could settle on drawing up your inventory by including each and every atom and noting else. But is there a general, neutral criterion that does not depend on any specific views concerning the ultimate structure of the world and the grounding relations that bind it together?

I myself favor the following: $:^{43}$

CI" Your inventory should include an entity you are committed to, $x$, if and only if $x$ does not overlap any other entity $y$ that is itself included in the inventory.

Intuitively, this captures the idea that your inventory should reflect a way of "partitioning" the reality you are committed to into an exhaustive collection of pieces. It should cover the world like a complete "tiling", with no gaps and no overlaps. There may be other ways of cashing out this intuition in terms of precise criteria for inventory drawing, and I think there is interesting work to be done in this connection. ${ }^{44}$ But there is one thing about CI" that I like, given the fundamental ten-

${ }^{43} \mathrm{CI}^{\prime \prime}$ is the criterion for Mereological Minimalism of Varzi [2000].

44 'Partitioning' is from Cotnoir [2013]; 'tiling' from Schaffer [2010]. 
sion I started with. For overlap involves quantification, and quantification is the key to existence: two things overlap if and only if there exists something that is part of both. So CI" does justice to my Lewisian instincts, but it does so on the grounds of my full-blown ontological credo. My Quinean heart is happy enough. ${ }^{45}$

\section{References}

Armstrong, David M., 1997, A World of States of Affairs, Cambridge: Cambridge University Press.

Baker, Lynne R., 2008, 'A Metaphysics of Ordinary Things and Why We Need It', Philosophy, 83: 5-24.

Baxter, Donald L. M., 1988, 'Identity in the Loose and Popular Sense', Mind, 97: 575582.

- 2005, 'Altruism, Grief, and Identity', Philosophy and Phenomenological Research, 70: 371-383.

- 2013, 'Identity, Discernibility, and Composition', this volume.

Berto, Francesco, and Carrara, Massimiliano, 2009, 'To Exist and to Count: a Note on the Minimalist View', Dialectica, 63: 343-356.

Bohn, Einar S., 2009, 'Must There Be a Top Level?', Philosophical Quarterly, 59, 193201.

Cameron, Ross P., 2007, 'The Contingency of Composition', Philosophical Studies, 136: 99-121.

- 2012, 'Composition as Identity Doesn't Settle the Special Composition Question', Philosophy and Phenomenological Research, 84: 531-554.

Cotnoir, Aaron J., 2013, 'Composition as General Identity', Oxford Studies in Metaphysics, 8: 294-322.

Feigl, Herbert, 1967, 'Postscript after Ten Years', in The "Mental" and the "Physical": The Essay and a Postscript, Minneapolis: University of Minnesota Press, pp. 133160.

Fine, Kit, 2001, 'The Question of Realism', Philosophers' Imprint, 1: 1-30.

Frege, Gottlob, 1884, Die Grundlagen der Arithmetik, Breslau: Köbner; Eng. trans. by John L. Austin, Foundations of Arithmetic, Oxford: Basil Blackwell, 1950.

Goodman, Nelson, 1956, 'A World of Individuals', in J. M. Bochenski, A. Church, and N. Goodman, The Problem of Universals. A Symposium, Notre Dame: University of Notre Dame Press, pp. 13-31.

${ }^{45}$ Many thanks to Aaron Cotnoir and Don Baxter for their helpful feedback. An earlier version of the paper was also presented at the Third PERSP Metaphysics Workshop in València, Spain, September 28, 2012, and I am grateful to my commentator, Jordi Valor, and to Marta Campdelacreu, Aurélien Darbellay, Dan López de Sa, Kathrin Koslicki, Thomas Sattig, and Alex Skiles for their constructive criticisms. 
Hirsch, Eli, 2002, 'Quantifier Variance and Realism', Philosophical Issues, 12: 51-73.

- 2011, 'Ontology and Alternative Languages', in D. Chalmers, D. Manley, and R. Wasserman (eds.), Metametaphysics, Oxford: Oxford University Press, pp. 231-259.

Hovda, Paul, 2005, 'How to Be an Atomist', unpublished ms.

- 2006, 'How Composition Could be Identity', unpublished ms.

Kim, Jaegwon, 1998, Mind in a Physical World, Cambridge, MA: MIT Press.

Kleinschmidt, Shieva, 2012, 'Many-One Identity and the Trinity', Oxford Studies in Philosophy of Religion, 4: 84-96.

Leśniewski, Stanisław, 1916, Podstawy ogólnej teoryi mnogości I, Moskow: Prace Polskiego Koła Naukowego w Moskwie; Eng. trans. by Dene I. Barnett, 'Foundations of the General Theory of Sets. I', in Leśniewski’s Collected Works, ed. by S. J. Surma et al., Dordrecht: Kluwer, 1992, Vol. 1, pp. 129-173.

Leonard, Henry S., and Goodman, Nelson, 1940, 'The Calculus of Individuals and Its Uses', Journal of Symbolic Logic, 5: 45-55.

Lewis, David K., 1991, Parts of Classes, Oxford: Basil Blackwell.

McDaniel, Kris, 2008, 'Against Composition as Identity', Analysis, 68: 128-133.

- 2010, 'Composition as Identity Does Not Entail Universalism', Erkenntnis, 73: 97100.

McKay, Thomas, 2006, Plural Predication, Oxford: Clarendon Press.

Merricks, Trenton, 2005, 'Composition and Vagueness', Mind, 114: 615-637.

Quine, Willard V. O., 1948, 'On What There Is', Review of Metaphysics, 2: 21-38.

- 1951, 'Ontology and Ideology', Philosophical Studies, 2: 11-15.

- 1958, 'Speaking of Objects', Proceedings and Addresses of the American Philosophical Association, 31: 5-22.

- 1960, Word and Object, Cambridge (MA): MIT Press.

Rosen, Gideon, and Dorr, Cian, 2002, 'Composition as a Fiction', in R. Gale (ed.), The Blackwell Guide to Metaphysics, Oxford: Blackwell, pp. 151-174.

Schaffer, Jonathan, 2010, 'Monism: The Priority of the Whole', Philosophical Review, 119: 31-76.

Sidelle, Alan, 2002, 'Is There a True Metaphysics of Material Objects?', Nô̂s, 36: 118145.

Sider, Theodore, 1993, 'Van Inwagen and the Possibility of Gunk', Analysis, 53: 285289.

- 2007, 'Parthood', Philosophical Review, 116: 51-91.

- 2013, 'Consequences of Collapse', this volume.

Slater, Matthew H., 2005, 'The Arbitrariness of Mereological Immoderation', colloquium paper delivered at the APA Pacific Meeting, San Francisco (CA), March 25.

Tarski, Alfred, 1935, 'Zur Grundlegung der Booleschen Algebra, I', Fundamenta Mathematicae, 24: 177-198; Eng. trans. by Joseph H. Woodger: 'On the Foundations of Boolean Algebra', in Tarski's Logics, Semantics, Metamathematics. Papers from 1923 to 1938, Oxford: Clarendon, 1956, pp. 320-341. 
van Inwagen, Peter, 1990, Material Beings, Ithaca: Cornell University Press.

- 1994, 'Composition as Identity', Philosophical Perspectives, 8: 207-220.

Varzi, Achille C., 2000, 'Mereological Commitments', Dialectica, 54: 283-305.

- 2006, 'The Universe Among Other Things', Ratio, 19: 107-120

- 2008, 'The Extensionality of Parthood and Composition', Philosophical Quarterly, 58: 108-133.

— 2009, 'Universalism Entails Extensionalism', Analysis, 69: 599-604.

- 2011, 'On Doing Ontology without Metaphysics', Philosophical Perspectives, 25: 407-423.

Wallace, Megan, 2013, 'Composition as Identity: Part 2', Philosophy Compass, 6: 817827.

Yi, Byeong-Uk, 1999, 'Is Mereology Ontologically Innocent?', Philosophical Studies, 93: $141-160$. 